\title{
Economic Policies: Is it Effective to Achieve Sustainability? A SVAR Evidence from Algeria
}

Hadjer Boulila ${ }^{1 *}$, Seyf Eddine Benbekhti', Benbouziane Mohemed ${ }^{2}$ and Fethi Benladgham ${ }^{2}$

${ }^{1}$ Department of Management and Commercial Sciences, University of Abou Bekr Belkaid, Chetouane, Algeria

${ }^{2}$ Department of Economics and Management, University of Abou Bekr Belkaid, Chetouane, Algeria

\begin{abstract}
Algeria has adopted many development plans to achieve economic, social and even environmental stability, from the Economic Recovery Program (2000-2004) to the new growth support program (2015-2019). In order to analyze and measure the impact of fiscal and monetary policy variables on three indicators of Sustainable Development under the conditions of globalization, an SVAR model has been used. The results of the structural impulse response and GRANGER causality have shown that economic policies in Algeria have an effective role in achieving economic and social development even with the absence of the impact of globalization and in turn have failed to achieve environmental development in the agricultural sector. However, Algerian authorities face a major challenge to achieve greater levels of development in a manner that includes all sectors and diversifies their economies to integrate into the international markets and benefit from the experiences of developed countries.
\end{abstract}

Keywords: Sustainable development; Fiscal policy; Monetary policy; Globalization, SVAR

\section{Introduction}

The concept of sustainable development is one of the most modern policies. It is regarded as a new term, but the idea of reaching development is back to the end of the Second World War however the first use of this word "sustainable development" was in 1980 by activists of a non-governmental organization called the World Wild Life Fund to preserve the nature. The concept of sustainable development was crystallized through the Environment and Development Conference held in 1992 in Brazil, where the latter seeks to reconcile environmental, demographic and natural balances. Following the World Summit on Sustainable, Development in Johannesburg in 2002 priorities were identified for sustainable development, Areas: Water, Energy, Health, Agriculture, Poverty, Trade, Information and Research.

Therefore, in the context of the economic and social transformations imposed by the trends of globalization and the World Trade Organization in addition to other international institutions, there is a need to develop the appropriate economic policies to achieve sustainable development. Coordinated with these international changes countries all over the world in general and Algeria in particular must provide efforts and opportunities to reach advanced levels of development, especially in light of the widening gap between its economies and economies of developed countries.

However, Algeria is in the process of completing its development projects in all its dimensions political, economic and social, where it has gone through several stages in achieving sustainable development since the year 1993 .

In early 1994, the Algerian authorities resorted to the International Monetary Fund and the World Bank to conclude the structural adjustment agreement. It began to implement structural reforms and debt-dependent development strategies as well as the hydrocarbons sector as the sole source of production and financing. These conditions created several disadvantages to the living standards of citizens, economic growth rates and the depletion of natural resources, what affected also public institutions and the whole national economy for several years. Moreover, with the oil boom in 2002, Algeria adopted a new policy of development, characterized by greater liberalization of the economy, and mobilizing the covenant monetary and fiscal policies. Where they activate these tools, to get rid of the dependency on hydrocarbons through diversification of entries.

Where monetary policy is a modern practice in the Algerian monetary system, which was the result of the issuance of the Money and Loan Act. The fiscal policy in Algeria was also characterized after the oil boom known as an expansionary fiscal policy, to develop growth rates, reduce the unemployment rate and preserve the environment and natural resources. These policies were used in the frame of many development strategies and programs and based on large financial packages directed to stimulate the dynamics of economic sectors Such as: agriculture, industry and tourism. where the Algerian authorities set up five programs, from the economic recovery program 2000-2004 (to stimulate national institutions and market demand) to the growth support program 2005-2009 (to expand the infrastructures) in addition to the growth program known as the five-year plan covering the period 2010-2014 (for the diversification of the Algerian economy and stimulation of the national production machinery). The final strategy was in 2015 "The new plan for the growth of the green Algeria 2015$2019 "$.

The aim of this study is to answer the question: "How effective is monetary and fiscal policy in achieving the objectives of sustainable development under the conditions imposed by globalization?" and to measure the effect of policies taken by the Algerian authorities in the goal of achieving advanced levels of development taking different sectors in consideration.

*Corresponding author: Hadjer Boulila, Department of Management and Commercial Sciences, University of Abou Bekr Belkaid, Chetouane, Algeria, Tel: +213778018233; E-mail: b.hadjer94@gmail.com

Received June 06, 2018; Accepted September 12, 2018; Published September 20, 2018

Citation: Boulila H, Benbekhti SE, Mohemed B, Benladgham F (2018) Economic Policies: Is it Effective to Achieve Sustainability? A SVAR Evidence from Algeria. J Glob Econ 6: 307. doi: 10.4172/2375-4389.1000307

Copyright: $\odot 2018$ Boulila $\mathrm{H}$, et al. This is an open-access article distributed unde the terms of the Creative Commons Attribution License, which permits unrestricted use, distribution, and reproduction in any medium, provided the original author and source are credited. 
So, this paper studies empirically the relative effectiveness of monetary and fiscal policies on sustainable development during globalization, unlike many previous papers that have focused on the effect of monetary or fiscal policy separately. And to reach this goal an alternative econometric model, namely Structural Vector Autoregressive model SVAR and granger causality test were adopted.

Here the approach is to build a model containing fiscal, monetary and other macroeconomic variables focusing on 3 sustainable indexes. Short-run restrictions on the non-fiscal variables are provided via the existing traditional SVAR restrictions. The fiscal policy shocks are identified using a minimal set of sign restrictions, leaving other relationships to be data determined. These restrictions are applied in conjunction with information from the co-integrating relationships between the macroeconomic variables to model the long run, allowing for both permanent and transitory components and a mixture of stationary and non-stationary variables [1]

This contribution is structured as follows. Section 1,2 reviews the corresponding academic literature. Section 3 introduces the data and first empirical results. Section 4 presents the findings of the causality analyses. Section 5 concludes with a summary.

\section{Literature Review}

The literature on the efficacy of monetary and fiscal policy on the achievement of sustainability is profuse and employs diverse econometric analysis, but most papers had studied these policies separately without taking globalization in consideration, there some previous studies as follow:

\section{The efficiency of monetary policy}

Leeper et al. investigated the role of monetary policy in USA using VAR model, where he found that a contractionary monetary policy shocks causes a rise in unemployment [1]. Alexius and Holmund analyzed the relation between monetary policy and unemployment in Sweden using an SVAR model and quarterly data of domestic output gap, unemployment, monetary condition index, technology and government deficit, Results suggest that expansionary monetary policy decreases unemployment. Abdurrahman empirically examined the role of monetary policy on economic activity in Sudan for the period 1990 to 2004 and found that monetary policy had a limited impact on economic activity during the period under consideration [2-4]. Author examined the effect of monetary policy on macroeconomic variables in Nigeria for the period 1986 to 2009 . The study showed that monetary policy had a significant influence in maintaining price stability within the Nigeria economy. While using an ARDL autoregressive distributed lag model to for co-integration, where they found that Croatian monetary policy is quiet limited in reducing unemployment.

\section{The efficiency of fiscal policy}

Author focus on the role of economic policy in the growth performance of the manufacturing sectors for 17 African countries over the period 1976-1993, they found that maintaining macroeconomic balance have significant role on manufacturing growth performance in Africa. Perotti investigates the effects of fiscal policy on GDP, inflation and interest rates in 5 OECD countries, using a structural Vector Autoregression approach, the main result is that both the decline in the variance of the fiscal shocks and the change in their transmission mechanism contribute to the decline in the variance of GDP [5]. Mountford and Uhlig, proposed and applied a new approach for analyzing the effects of fiscal policy using vector autoregressions, using US quarterly data from 1955 to 2000 [6]. They found that deficitfinanced tax cuts work best among these three scenarios to improve GDP, with a maximal present value multiplier of five dollars of total additional GDP per each dollar of the total cut in government revenue 5 years after the shock. It is examined the effect of fiscal policy on sectoral output growth in Nigeria for the period of 1970-2013 using an ARDL model, where the results showed that total fiscal expenditures have positively contributed to all sectors output with exception of agricultural sector.

\section{Globalization and development}

Sachs and Warner attribute the region's poor economic performance to geographical factors and inappropriate economic policies $[7,8]$. In particular, they argue that the lack of international integration is an obstacle to better performance. Edwards Openness may induce economic growth in several ways, for example, by increasing a country's level of specialization or by positively affecting innovation and technological diffusion [9]. Empirical evidence suggests that trade openness may indeed positively affect economic performance. Collier and Gunning similarly suggest that geographical disadvantages negatively affect economic growth in SSA [10]. They argue that poor economic policies also impair growth, for example, manifesting in a lack of trade openness, poor infrastructure, or the underdevelopment of financial and product markets. Gries et al. adopted contribution tests for causality between trade openness and economic development for 16 Sub-Saharan African countries [11]. The study indicates trade openness have swayed economic growth.

However, the impact of monetary and fiscal austerity on unemployment, GDP per capita and agriculture which represent some sustainability indexes taken under investigation into our study doesn't exists relatively, all studies discusses the impact of each variable separately on one macroeconomic variable without taking in consideration the globalization.

\section{Methodology and Results}

\section{Data}

In view of the nature of the study and the objectives that it seeks to achieve, Econometric measurement techniques were used to construct the SVAR "structural autoregressive model" that explains the impact of economic policies instruments and globalization on sustainable development. Using 3 equations representing different development dimensions which are: gross domestic product per capita "personal income" as an economic index for development, unemployment as a social dimension and agriculture sector as an environment dimension. In addition to macroeconomic variables presenting economic policies and globalization. This investigation used annual data extracted from World Bank database and the Ministry of finance, for the period of 1990-2016 (Table 1).

\section{Methodology}

A structural VAR (SVAR) uses additional identifying restrictions and estimation of structural matrices to transform VAR errors into uncorrelated structural shocks. Obtaining structural shocks is central to a wide range of VAR analysis, including impulse response, forecast variance decomposition, historical decomposition, and other forms of causal analysis $[12,13]$.

The SVAR structural model is written mathematically as follows:

$A X_{t}=C(L) X_{t-1}+\beta e_{t}$ 


\begin{tabular}{|c|c|c|}
\hline \multicolumn{2}{|l|}{ Variables } & \multirow{2}{*}{$\begin{array}{l}\text { Specification } \\
\text { Represents the discount rate tool,which is considered one of the most effective and used monetary policies } \\
\text { in Algeria. }\end{array}$} \\
\hline $\begin{array}{l}\text { Macroeconomic variables representing monetary } \\
\text { and fiscal policies }\end{array}$ & Dr & \\
\hline & PEX & $\begin{array}{l}\text { Government spending, a tool of fiscal policy and a tool of the austerity policy adopted by Algeria after the } \\
\text { recent oil crisis. }\end{array}$ \\
\hline & $\mathrm{T}$ & Taxes revenue in Algeria as a fiscal policy \\
\hline \multirow[t]{3}{*}{ Sustainable development dimension } & GDPC & $\begin{array}{l}\text { Gross domestic product per capita represents the indicator of economic development (GDP/global } \\
\text { population) }\end{array}$ \\
\hline & UM & Unemployment rate as an indicator for social development. \\
\hline & AGC & Added value of agriculture as an environment development indicator. \\
\hline Globalization & OPN & $\begin{array}{l}\text { The trade openness is one of the most important indicators of globalization and the most important } \\
\text { condition to ensure trade liberalization }\end{array}$ \\
\hline
\end{tabular}

Source: Author's own.

Table 1: Variables specification.

\begin{tabular}{|c|c|c|c|c|}
\hline \multirow[t]{2}{*}{ Variable } & \multicolumn{3}{|c|}{ ADF stationarity test (prob) } & \multirow[t]{2}{*}{ Results } \\
\hline & Level & $1^{\text {st }}$ difference & $2^{\text {nd }}$ difference & \\
\hline GDPC & 0.9945 & 0.0272 & - & Stationary at first difference \\
\hline UM & 0.9369 & 0.0346 & - & Stationary at first difference \\
\hline AGC & 0.9996 & 0.2856 & 0000 & Stationary at ${ }^{2 n d}$ difference \\
\hline PEX & 0.4924 & 0.0004 & - & Stationary at first difference \\
\hline DR & 0.6319 & 0.0044 & - & Stationary at first difference \\
\hline$T$ & 0.0787 & 0.0002 & - & Stationary at first difference \\
\hline OPN & 0.4943 & 0.0011 & - & Stationary at first difference \\
\hline
\end{tabular}

Table 2: ADF results.

$\mathrm{Xt}$ is the vector of endogenous variables. For our study it's represented by the variables of the three models:

the first model Xt consists of: GDPC, PEX, DR, T, OPN.

For the second and third models, GDPC is replaced with UM and AGC, respectively.

$e_{t}$ represents the vector of the structural residues.

A is a square matrix of main diameter elements are equal to 1.

$\mathrm{C}(\mathrm{L})$ is the vector of lags that determines the number of delays in the model.

The restrictions placed on the contemporaneous relationships among the variables are characterized by eqn. (1), which is the lefthand side of the standard SVAR representation (eqn. (2) Appendix A).

The main steps of an SVAR model are:

- Unit root test variables must be $\mathrm{I}(0), \mathrm{I}(1)$ or a mixture of both.

- Estimating the VAR model after determining the lag lengths.

- Estimating the SVAR model after placing structural matrix constraints.

- Extraction of structural impulse response functions and causal testing.

\section{Results}

\section{Unit root test}

We have used ADF augmented Dickey Fuller test for stationary, where this test is the most important step before estimating any model. If the variables in the regression model are not stationary, then it can be proved that the standard assumptions for asymptotic analysis will not be valid. In other words, the usual " $t$-ratios" will not follow a t-distribution, so we cannot validly undertake hypothesis tests about the regression parameters.
From Table 2 we note that the probability of calculated values is greater than the critical value (0.05) for all variables and therefore we accept null hypothesis h0, which states the existence of a unit root in all time series.

After the same test, but on the first differences, we observe that all time series are stationary except the AGC whose calculated value probability $(0.2856)$ is higher than the critical value $\alpha=0.05$.

\section{VAR estimation}

From Table 3 First we will select lag to VAR for the three models, because this is a very important step. The lag order of the VAR model is selected based on Akaicke Criteria (AIC) and Schwarz (SC).

\section{SVAR estimation, impulse responses and granger causality}

Before estimating SVAR model we must estimate structural matrices to transform VAR errors into uncorrelated structural shocks. Restrictions on A and B (short run matrices) and $\mathrm{F}$ (long run matrices) take the form of assumptions about the structure of contemporaneous feedback of variables in the SVAR and assumptions about the correlation structure of the errors, respectively (Table 1; Appendix A).

Impulse responses: From Figure 1 we noticed that the response of GDPC to the shock of government expenditure is a positive response, generally insignificant during the first 3 years to become significant from the fourth year and up to 0.2 but not exceeding two years. It also responds to the discount rate shock instrument in the first two years, up to 0.4 then it becomes insignificant in year 3 , but quickly becomes a negative response of up to 0.5 for 3 years Figure 2. Otherwise, GDPC recorded a continuous negative response to tax policy shocks up to the eighth year as it became insignificant 0.01. Finally, it response to the trade openness index shocks during the first years continues to respond positively to 0.6 and then becomes a fluctuating response between positive and negative.

Non-significant negative response of UM to the government expenditure shocks is obvious from Figure 3 during the first 3 years 
Citation: Boulila H, Benbekhti SE, Mohemed B, Benladgham F (2018) Economic Policies: Is it Effective to Achieve Sustainability? A SVAR Evidence from Algeria. J Glob Econ 6: 307. doi: 10.4172/2375-4389.1000307

Page 4 of 7

\begin{tabular}{|c|c|}
\hline Model (equation) & Lag length \\
\hline GDPC model & 2 \\
\hline UM model & 2 \\
\hline AGC model & 1 \\
\hline Source: Author's own depending on eviews 9. & \\
\hline
\end{tabular}

Table 3: Lag length results.

Response to Cholesky One S.D. Innovations \pm 2 S.E.

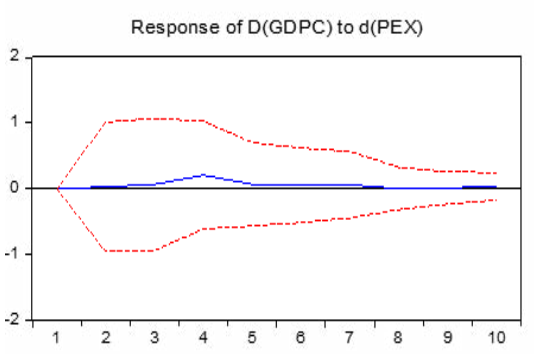

Response of $d(G D P C)$ to $D(D R)$
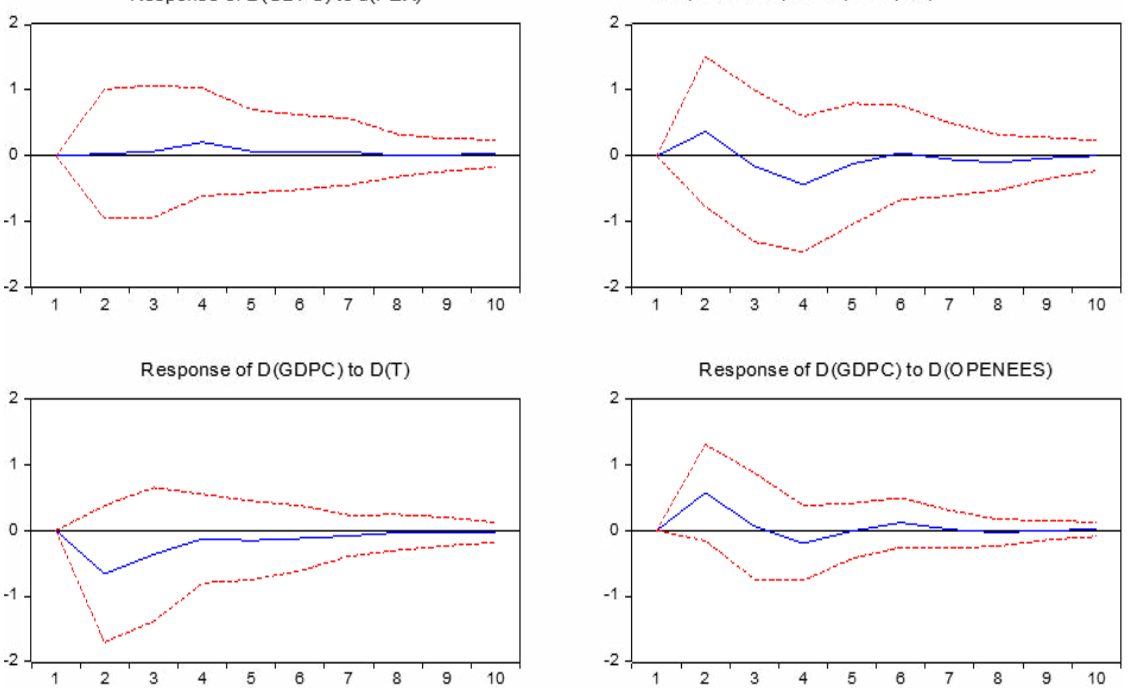

Figure 1: Response of GDPC economic development model.

Response to Cholesky One S.D. Innovations \pm 2 S.E.

Response of $d(U M)$ to $d(P E X)$

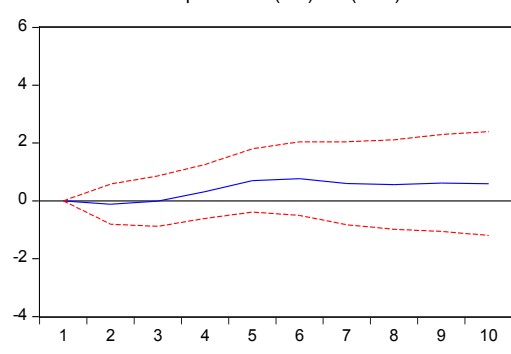

Response of $d(U M)$ to $d(T)$

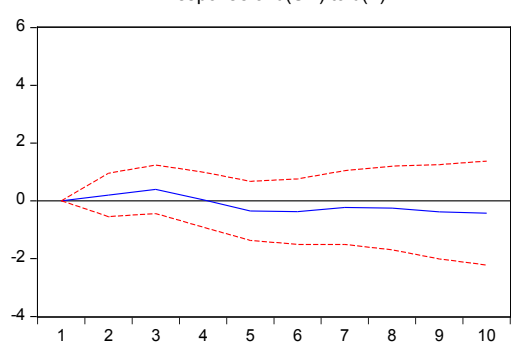

Response of $d(U M)$ to $d(D R)$

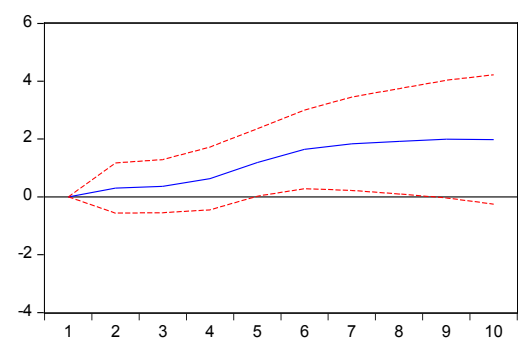

Response of $d(\mathrm{UM})$ to $\mathrm{d}(\mathrm{OPN})$

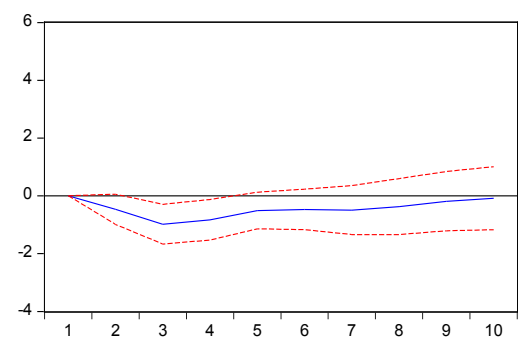

Figure 2: Response of UM.

and then it becomes a positive response of 0.8. Due to the shocks of the discount rate instrument, there was a significant positive response for ten years and reached a maximum of (2) in the tenth year. The response of unemployment to the shock of tax policy was positive during the first 4 years (0.4) and negative (0.4) for the rest of the period.
Finally, trade openness shocks led to a negative response for 8 years until it became insignificant in the years $9^{\text {th }}$ and $10^{\text {th }}$ year.

While Table 4 shows that AGC responds to the shock of government expenditure in a negatively up to 2.1 for a period of two years and then a 
Response to Cholesky One S.D. Innovations \pm 2 S.E.
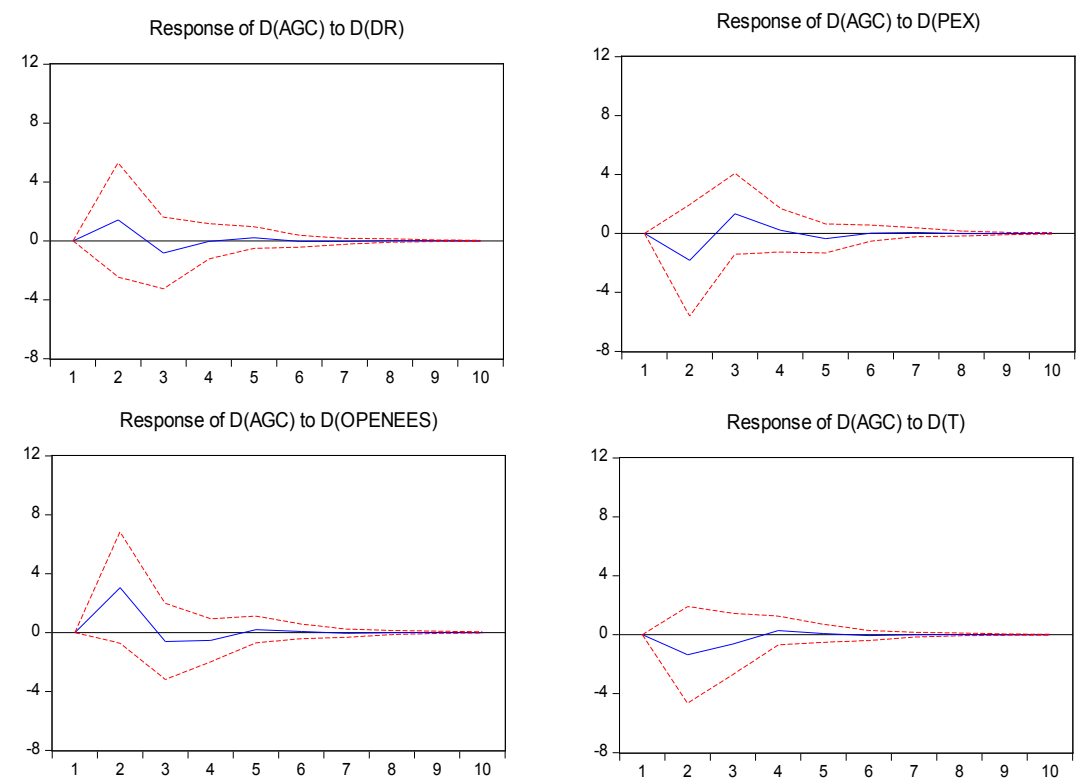

Figure 3: Response of AGC.

\begin{tabular}{|c|c|c|c|c|}
\hline \multicolumn{2}{|c|}{ Model } & \multicolumn{2}{|c|}{ Probability } & Decision \\
\hline \multirow{4}{*}{ GDPC } & \multirow{4}{*}{$\leftarrow$} & PEX & 0.0641 & Causal relationship exists \\
\hline & & $\mathrm{Dr}$ & 0.0099 & Causal relationship exists \\
\hline & & $\mathrm{T}$ & 0.2663 & No causal relationship \\
\hline & & OPN & 0.2052 & No causal relationship \\
\hline \multirow{4}{*}{ UM } & \multirow{4}{*}{$\leftarrow$} & PEX & 0.0962 & Causal relationship exists \\
\hline & & $\mathrm{Dr}$ & 0.0001 & Causal relationship exists \\
\hline & & $\mathrm{T}$ & 0.2264 & No causal relationship \\
\hline & & OPN & 0.0002 & Causal relationship exists \\
\hline \multirow{4}{*}{ AGC } & \multirow{4}{*}{$\leftarrow$} & PEX & 0.2469 & No causal relationship \\
\hline & & $\mathrm{Dr}$ & 0.7324 & No causal relationship \\
\hline & & $\mathrm{T}$ & 0.3493 & No causal relationship \\
\hline & & OPN & 0.2209 & No causal relationsh \\
\hline \multicolumn{5}{|c|}{$\begin{array}{l}\text { Critical value } 10 \% \\
\leftarrow \text { direction of causality. } \\
\text { Source: author's own depending on Eviews } 9 .\end{array}$} \\
\hline
\end{tabular}

Table 4: Granger causality results

positive response in the $3^{\text {rd }}$ and $4^{\text {th }}$ where it was estimated at 1.5 followed by a non-significant response in the remaining period. In addition, a volatile response to the shocks of the discount rate instrument was in the first five years, where a positive response was recorded in the first 3 years, reaching 1.8, and a negative response in both the 4 th and 5 th years was estimated at 1.2. In addition AGC response to tax policy shocks is a negative response with a maximum value of -1.8 and continued for the first 4 years to become insignificant. Finally, significant positive response of AGC to trade-opening shocks was estimated at 3 in the second year and negative response after recording $(-0.6)$ for two years after which it became a non-significant response.

Granger causality: Granger defined the causality relationship based on two principles: First, The cause happens prior to its effect. Second, The cause has unique information about the future values of its effect. The results are summarized in Table 3.

\section{Finding Discussion}

From the previous results, we conclude that economic policies have a positive effect on economic and social development during globalization. Main findings are explained as follow:

The spending policy affects individual income. The latter is calculated by dividing the gross national income by the population [14]. Therefore, any change in GDP leads to a change in GDPC. Public spending (on investment and consumption), leads to a direct increase in national income. On a side, the impact of spending on wages and salaries, as well as the increase in the productivity of the state, is seen as the increase in social expenditure (health, education, culture and technical training of workers) increases the level of employment and thus increases the quantity and quality of production. Other side, spending is one of the most important components of the real demand, which has a direct impact on the volume of production, provided that the production system has flexibility. However, Algeria's economic development is somewhat weak [15]. Despite the development programs, five-year plans and massive financial allocations aimed at stimulating the dynamism of promising economic sectors, this has led to small increases in growth rates. Non-productive or poorly produced 
does not comply with international standards, any way this results are contrary to Perottie's (2004) who found that fiscal policy have a negative effect on GDP [5].

According with Osinowo Decreasing unemployment rates as a social development indicator is one of the most important objectives of fiscal policy, especially the policy of spending. For example, high rates of unemployment means low effective demand, here comes the role of spending policy to achieve economic recovery [16]. either through economic subsidies to producers that contribute to increasing the production and the decline of unemployment (as a solution in the short term), or the development of financial plans in the long term require the establishment of new industrial cities and the provision of all basic services allowing for new employment opportunities.

The discount rate as a monetary policy instrument, has a positive effect on economic development GDPC because the mechanism of the discount rate works to increase or decrease the volume of cash circulation by affecting the loans granted by the commercial banks. Therefore reducing Discount rate will lead to a decline in interest rate and thus increase the attentiveness of institutions on investment loans which will increase the frequency of production and Rising GDP [17]. This results are similar to Abdurrahman's [4]. This monetary policy also affects the size of unemployment in Algeria as this tool is one of the most important tools of monetary policy, which contributed to the provision of investment loans for young people with special advantages for the adoption of small and medium enterprises (ANSEGE, ANSEG, CNAC ..) these results is contrary to Sims and Zha and agreed with the results $[1,3]$.

However, the relation between economic policies and agriculture is not supported empirically what is agreeing with Osinowo. Where In spite of the subsidies and the great support for this sector from the advanced agricultural machinery, the provision of fertilizers in to the implementation of barrage projects and the diversification of agricultural loans, but the lack of supervision and the absence of following the process of farmers led to non-exploitation of these resources. On the other hand, what marginalized the role of economic policies is the unavailability of the necessary labor; and the qualified farmers because of the lack of training in the agricultural and technological fields as well as the mentality of the Algerian citizen, which is considered that the profession of agriculture may be lacking.

Contrary to Thomas Gries, who found that trade openness as an indicator of globalization; have a positive effect on GDP [11]. Nevertheless, for our study, trade openness does not have any impact on the economic development in Algeria because of the absence of local product, especially food production and technology and for the reason that this country depends on imports to response to the needs of citizens. Therefore, the absence of domestic product competition and the absence of appropriate climate for foreign investors due to the restrictions imposed and complex financial laws [18]. However, globalization affects the unemployment rates as Algeria has included foreign investments and international partnerships in addition to multinational companies and also used foreign companies to complete major infrastructure projects (such as the East-West Highway), which led to the provision of additional positions.

\section{Conclusion}

Algeria, like others, is striving to maintain economic, social and environmental stability by pursuing plans aimed at achieving sustainable development. However, despite the great efforts, Algeria has not yet achieved the ideal rate of development and has not kept pace with the developments of developed countries because they are not integrated into globalization. The most important results of the SVAR tests of structural response and causal testing have showed that Algerian economic policies had an impact on the level of economic and social development, especially the discount rate and fiscal policy, while it still unable to promote economic sectors outside the hydrocarbons. Algerian plans wasn't effective because of the large dependence of oil and the correlation of all macroeconomic variables with the changes in oil prices, this has also led to weak trade openness due to the lack of diversification of exports. However, this does not ignore the impact of globalization on job creation by foreign companies and multinationals, which has reduced unemployment rates in Algeria.

Perhaps the most important recommendations that must be made by decision-makers are:

- The need to reorient public expenditures in a way that targets more productive sectors in order to create new industrial cities by providing facilities that stimulate the investment of human thought in terms of investment in the framework of entrepreneurship in order to diversify the economy.

- The formation of human resources to correspond with the developments and requirements of technological and vocational advancement in order to promote the economic sectors outside the hydrocarbons sector so that the outputs of goods and services of high quality.

- Attention to the environmental-economic aspect, so that the interest in tourism ensures the preservation of the environment through the attention of the authorities to take care of the scenic landscape on the one hand and to maintain the cleanliness of cities and neighborhoods so that Algeria is a destination attracts tourists from all over the world.

- Supervision, follow-up and training for the owners of investment projects supported by the state, such as the institutions of saffron and medium and agricultural development in order to exploit this support to the fullest.

- Ensure the independence of the Central Bank in order to achieve better performance of monetary policy.

\section{References}

1. Leeper EM, Sims CA, Zha T, Hall RE, Bernanke BS (1996) What does monetary policy do? Brookings papers on economic activity 1996: 1-78.

2. Alexius A, Holmlund B (2007) Monetary policy and Swedish unemployment fluctuations. CESifo Working Paper No. 2044, 2: 1-26.

3. Alexius A, Holmlund B (2008) Monetary policy and Swedish unemployment fluctuations. Working Paper 2: 1-26.

4. Abdulrahman BMA (2010) The role of monetary policy on economic activity in Sudan: An empirical investigation 1990-2004. J Human Sci 44: 1-21.

5. Perotti R (2004) Estimating the effects of fiscal policy in OECD countries. IGIER Working Paper No. 276. pp :1-60.

6. Mountford A, Uhlig $\mathrm{H}$ (2009) What are the effects of fiscal policy shocks? J App Econ 24: 960-992.

7. Sachs JD, Warner AM (1997a) Fundamental sources of long-run growth. Am Econ Rev 87: 184-188.

8. Sachs JD, Warner AM (1997b) Sources of slow growth in African economies $J$ Afr Econ 6: 335-376.

9. Edwards S (1998) Openness productivity and growth: what do we really know? Econ J 108: 383-398. 
Citation: Boulila H, Benbekhti SE, Mohemed B, Benladgham F (2018) Economic Policies: Is it Effective to Achieve Sustainability? A SVAR Evidence from Algeria. J Glob Econ 6: 307. doi: 10.4172/2375-4389.1000307

Page 7 of 7

10. Collier P, Gunning JW (1999) Why has Africa grown slowly? J econ Perspec 13: 3-22.

11. Gries T, Kraft M, Meierrieks D (2009) Linkages between financial deepening trade openness and economic development: causality evidence from SubSaharan Africa. World development 37: 1849-1860.

12. Martin V, Hurn S, Harris D (2013) Econometric modelling with time series. Cambridge Books.

13. Harris JM (2000) Basic principles of sustainable development. Dimensions of Sustainable Development; WORKING PAPER 00-04, Global Development And Environment Institute, pp: 1-26.
14. Bossel H (1999) Indicators for sustainable development: Theory method applications. IISD, pp: 1-138.

15. Castelnuovo E (2010) Monetary Policy Shocks Cholesky Identification and DNK Models: An Empirical Investigation for the US. pp:1-39.

16. Ezeji CE (2014) The Impact of Macro-Economic Indicators on Domestic Credit in Commercial Banks in Nigeria. Int J Empir Financ 2: 34-44.

17. Gollin D, Parente S, Rogerson R (2002) The role of agriculture in development. Am Econ Rev 92: 160-164.

18. Soubbotina TP (2004) Beyond economic growth: An introduction to sustainable development World Bank Publications. 